\title{
Research and Design of Submerged Vehicle's Propeller Blade
}

\author{
Sanjeev Gaur
}

\begin{abstract}
Recently, Fiber Reinforced Composite is used for making a propeller blade to develop its performance by increasing the payload and underwater speed of the vehicle. As a consequence of its feathery weight \& high strength, numerous scholars/scientist substituted the conventional metallic material with composite material for crafting the propeller. In the contemporaneous work, predictions of pressure circulation around the profile of a propeller blade as a result of hydrostatic pressure difference are existing. Static structural stress investigation was executed for a single combination i.e. carbon fiber reinforced plastic (CFRP) \& for hybrid condensation (a combination of two composite materials) i.e. CFRP \& Glass Fiber Reinforced Plastic (GFRP). ANSYS APDL software is used to conclude von Mises pressure developed in the propeller blade. The result has been given away that it is more beneficial to use the hybrid blended material than the composite one. The weight value of propeller blade is found to be lower for the hybrid complexes, proposing the intrinsic worth of the contemporaneous work.
\end{abstract}

Keywords: Propeller blade, (CFRP), (GFRP), hydrostatic pressure difference, hybrid composite

\section{INTRODUCTION}

In this progressive era of science \& technology, using our non-traditional resources as a source of energy has become an important issue. One of these important areas is an underwater maritime platform where much research effort has been done to develop underwater vehicles and to look at its different impacts. A propeller is one of the vital parts of an underwater vehicle for a propulsion/forward motion system [1]-[4].

The strong point of the propeller blade is lone of the most essential factors for the appropriate enactment of the underwater vehicle. Propeller blade is usually made of conventional metabolic elements like as aluminum alloy, stainless steel etc. Now a day due to light weight \& prolonged durability, composite materials are used instead of metallic component [5]-[8].

In the past literature, Rao and Reddy concluded that composite propeller blades are safer in case of resonance onions in their harmonic analysis. Vibration defect can also be controlled in case of dampness effect any more [9], [10].

Khan et al. observed shear stress b/w laminar for composite materials considering different number of layers and found that the layers are strongly correlated. Eigen value investigation illustrates that composite material is $80.5 \%$ more natural in nature than aluminum propeller [11].

Ganesh et al. have carried out static and modal analysis for aluminum propeller and propeller (carbon-reinforced plastic). From the analysis, it is witnessed that the blade

Revised Manuscript Received on September 14, 2019.

Dr. Sanjeev Gaur, Department of Mechanical Engineering, Sanskriti University, Uttar Pradesh, India.(Email: sanpubip@gmail.com) definition in the case of a blended propeller is not significantly smaller compared to aluminum [12].

Yeo et al. predict stress distribution around a propeller blade by FEA technique. Considering a three laminated propeller and stainless steel as the material, a hydrodynamic study is approved out. By means of rising RPM/rotational speed, the modified pressure is also increased after 3000 rpm, exceeding its critical pressure [13], [14].

\section{MODELLING OF PROBLEM BLADES}

CATIA V5 application is employed for modeling the propeller blade. The shape design module is employed to generate a 3D model of propeller blade. The model is created by taking into account external diameter of propeller blade as $200 \mathrm{~mm}$ and the inner diameter (i.e. diameter of propeller) as $30 \mathrm{~mm}$. The blade corners get a round shape with a radius of $40 \mathrm{~mm}$. The thickness of the applied blade for the purpose of analysis is $1 \mathrm{~mm}$. A 3-D replica of the propeller vane is shown in Figure 1.

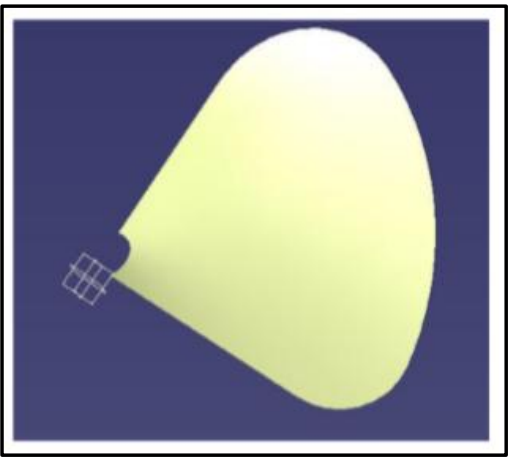

Figure 1. 3-D replica of propeller blade.

\section{Mesh Generation}

The meshed propeller vane/blade is displayed in Figure 2. The element used for meshing is 4 element 141 shell. Considering $2 \mathrm{~mm}$ element size created in preprocessor meshing module of ANSYS APDL [11], [15].

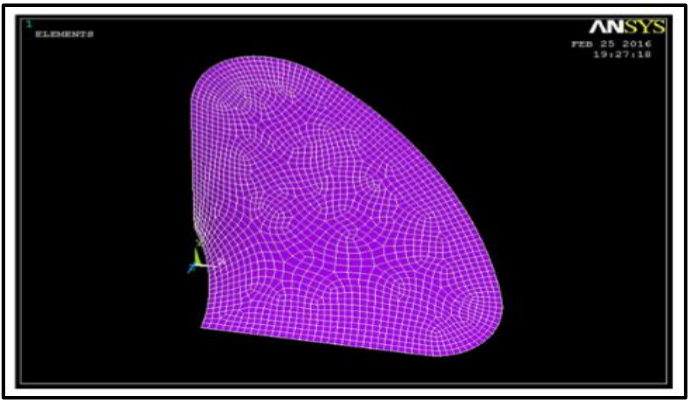

Figure 2. Meshed propeller blade 


\section{Boundary Condition}

The circumference of the blade that meets the center point is fixed for each translation level of freedom. During blade propeller analysis considered as cantilever beam. Loads are applied approximately $1 / 3$ distance from blade tip i.e. at $0.7 \mathrm{R}$ to $0.75 \mathrm{R}$, wherever $\mathrm{R}$ is propeller blade radius. The applied load size is equal to $4000 \mathrm{~N}$ for static structural analysis and loads are distributed evenly among selected and normal nodes to the blade face.

\section{Material Characteristics of Composites}

The composites that are given in the table are described with their physical properties. The physical properties of the composites are presented in Table 1.

\begin{tabular}{|c|c|c|}
\hline Composite material & CFRP & GFRP \\
\hline Young's modulus $\mathrm{E}_{\mathrm{X}}(\mathrm{Gpa})$ & 22.925 & 120 \\
\hline Young's modulus $\mathrm{E}_{\mathrm{Y}}(\mathrm{Gpa})$ & 22.925 & 10 \\
\hline Young's modulus $\mathrm{E}_{\mathrm{Z}}(\mathrm{Gpa})$ & 12.4 & 10 \\
\hline Poisson's ratio NUXY & .12 & .16 \\
\hline Poisson's ratio NUYZ & .2 & .2 \\
\hline Poisson's ratio NUZX & .2 & .16 \\
\hline Rigidity modulus $\mathrm{G}_{\mathrm{XY}}(\mathrm{Gpa})$ & 4.7 & 5.2 \\
\hline Rigidity modulus $\mathrm{G}_{\mathrm{YZ}}(\mathrm{Gpa})$ & 4.2 & 3.8 \\
\hline Rigidity modulus $\mathrm{G}_{\mathrm{ZX}}(\mathrm{Gpa})$ & 4.2 & 6 \\
\hline Density(p)(gm/cc) & 1.8 & 1.6 \\
\hline
\end{tabular}

Table 1. Physical Characteristics of materials

\section{RESULT AND DISCUSSION}

During analysis, various number of layers such as 4 rows, 8 rows, 12 rows and 16 layers are considered for both homogeneous and hybrid products. The thickness of each dressing cover is considered. In the case of hybrid coupling the amount of CFRP and GFRP fluctuates respectively as illustrated in Figure 4. Blended fiber orientation is given as $45^{\circ}$ and $-45^{\circ}$ respectively as shown in Figure $3 \&$ Figure 4.

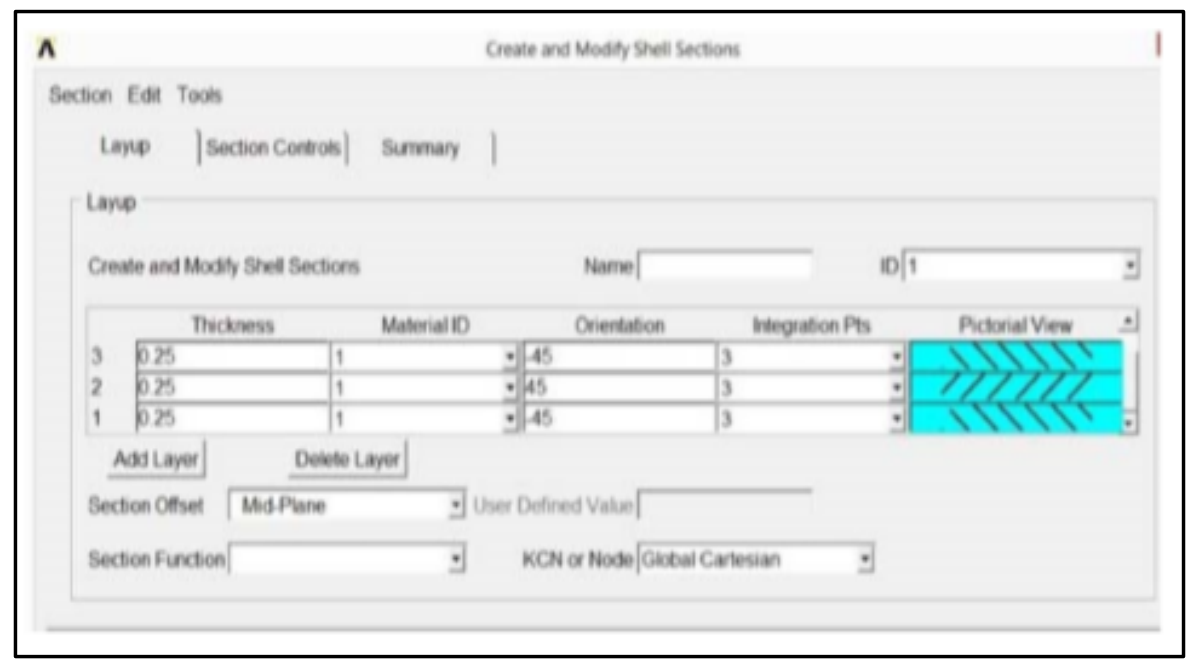

Figure 3. Various layer\& fibre positioning of CFRP (4 layers)

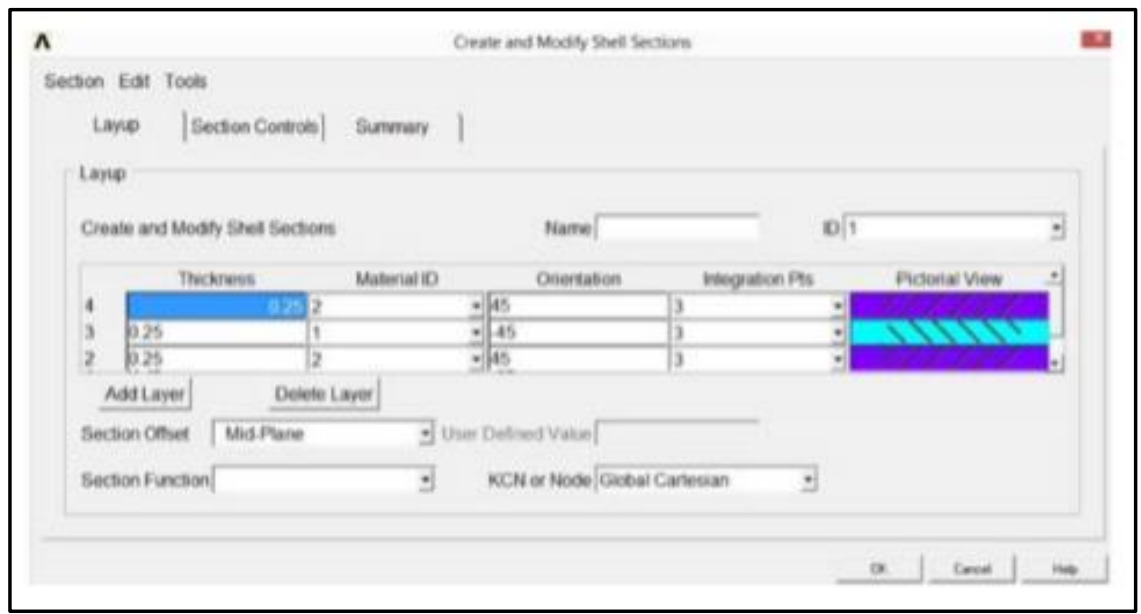

Figure 4. Various layer and orientation of hybrid composite (4 layers) 


\section{Static Structural Analysis}

Structural analysis is performed for four cases for both single CFRP and hybrid compound propeller considering various layers and corresponding illumination and stress are observed.

\section{Case 1: analysis result for 4 layers}

The maximum direction for a single CFRP propeller blade is $0.802 \mathrm{~mm}$ in a $\mathrm{z}$ direction that is, customary to the blade front $\&$ the maximum von Mises pressure is $22.1 \mathrm{~N} /$ $\mathrm{mm} 2$. In the case of a hybrid propeller mounting shaft at $0.9213 \mathrm{~mm} \&$ maximum von Mises pressure is $21.1 \mathrm{~N} /$ $\mathrm{mm} 2$. Both illumination \& von Mises stresses are presented in Figure 5, Figure 6, Figure 7, \& Figure 8.

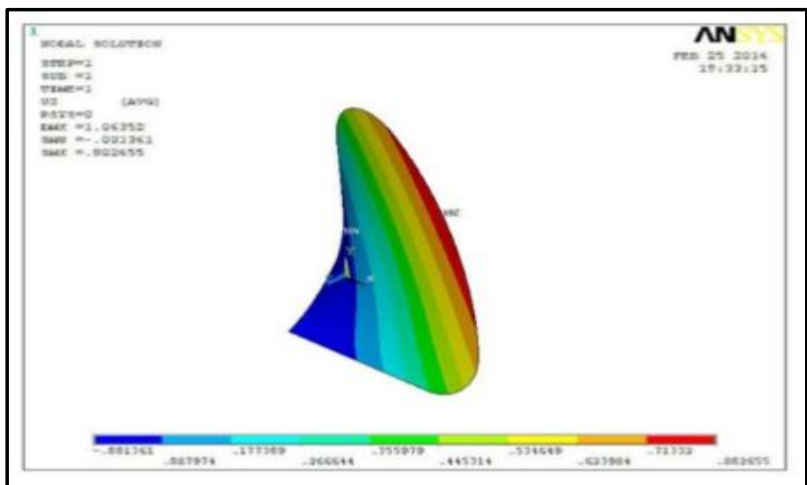

Figure 5. Deflection of CFRP composite blade (4 layers)

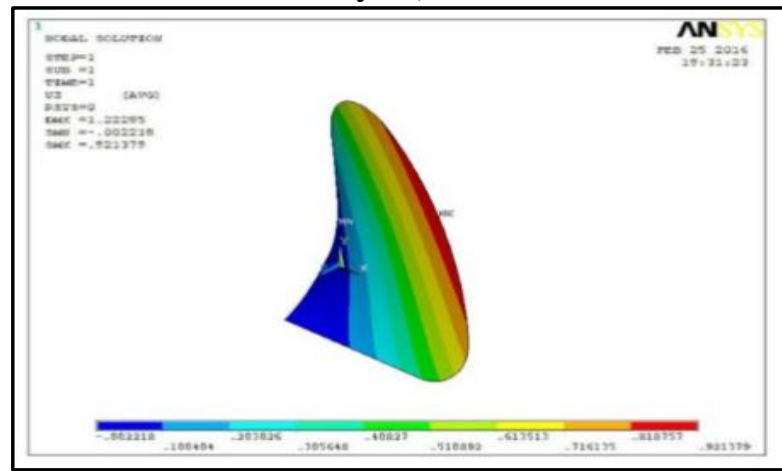

Figure 6. Deflection of hybrid compound blade (4 layers)

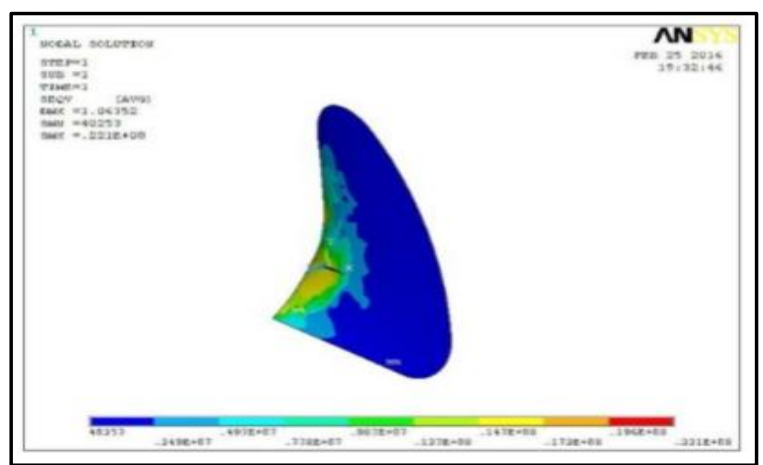

Figure 7. Max von/misses stress for CFRP propeller blade (4 layers)

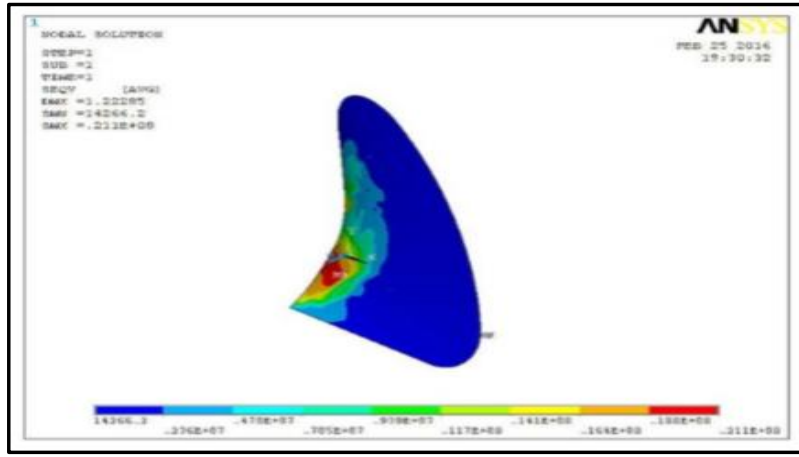

Figure 8. Max von Mises stress for hybrid composite propeller blade (4 layers)

Case 2: Analysis result for 8 coatings

Here the thickness of each cover is estimated to be 0.125 $\mathrm{mm}$. The maximum illumination for a single CFRP propeller blade is $0.75 \mathrm{~mm}$ in $\mathrm{z}$ direction i.e. normal to the blade face \& max von Mises pressure is $23.7 \mathrm{~N} / \mathrm{mm} 2$. In the case of a hybrid propeller shaft at $0.79 \mathrm{~mm}$ and maximum von Mises pressure is $20.1 \mathrm{~N} / \mathrm{mm} 2$. Both illumination and von Mises stresses/pressure are displayed in Figure 9, Figure 10, Figure 11 , $\&$

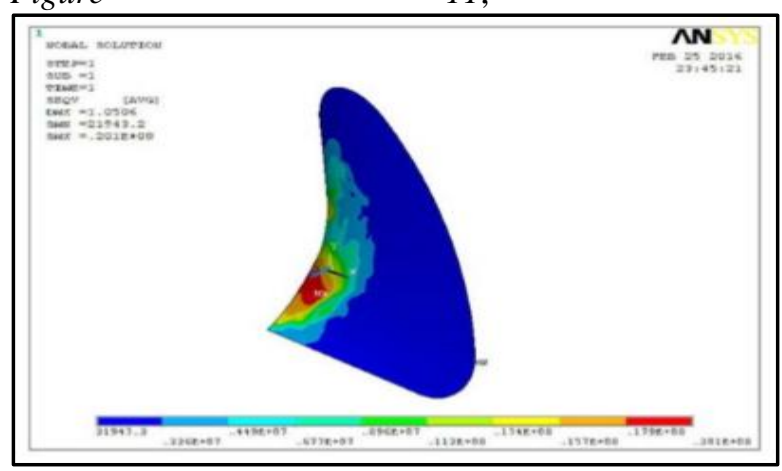

Figure 12.

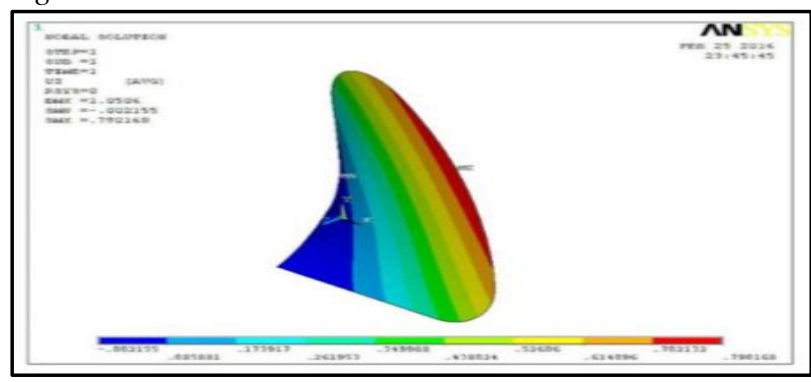

Figure 9. Deflection of CFRP blade (8 layers)

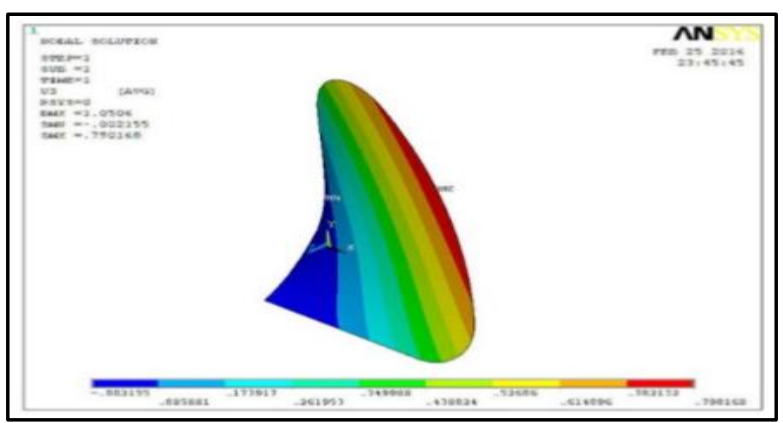

Figure 10. Deflection of hybrid composite blade $(8$ layers) 


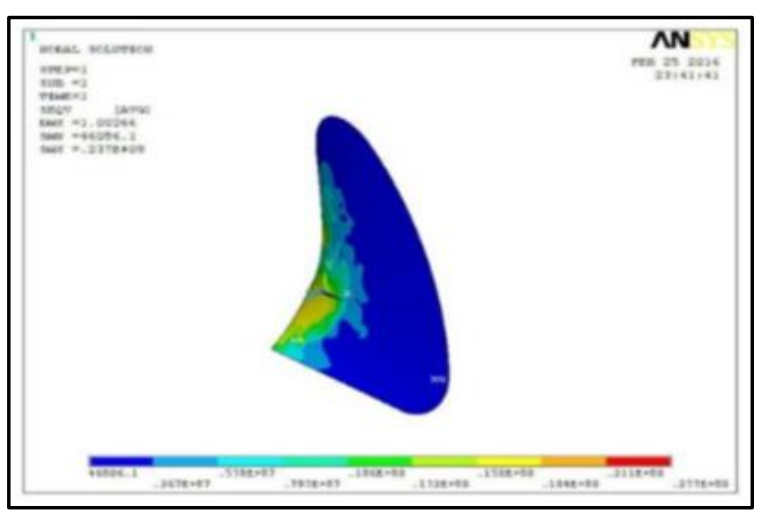

Figure 11. Max von/Mises stress for CFRP propeller blade (8 layers)

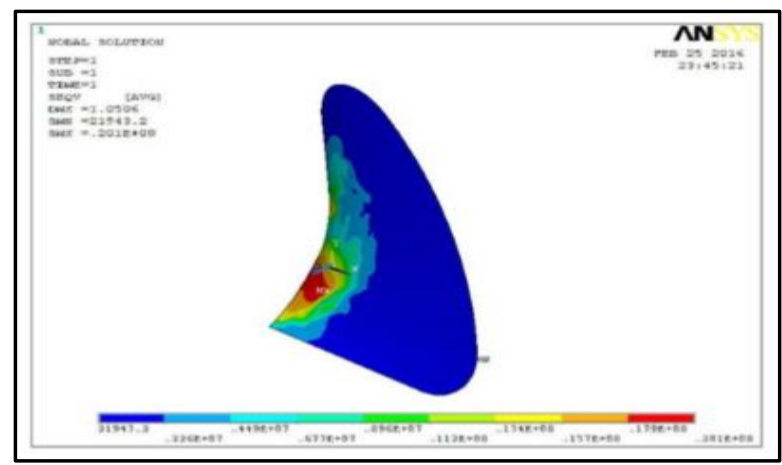

Figure 12. Max von Mises pressure/stress for hybrid composite propeller blade (8 layers)

Case 3: Analytical result for 12 coatings

Here the width of each coating is estimated as $0.0833 \mathrm{~mm}$. The maximum illumination for a single CFRP propeller blade is $0.7534 \mathrm{~mm}$ in the direction of $\mathrm{z}$ i.e. normal to the blade front and the max von Mises pressure is $25.7 \mathrm{~N} /$ $\mathrm{mm} 2$. In the circumstance of a hybrid propeller mounting shaft at $0.702 \mathrm{~mm}$ and von Mises pressure is $22.7 \mathrm{~N} / \mathrm{mm} 2$. Both illumination \& von Mises pressure/stresses are shown in Figure 13, Figure 14, Figure 15, \&

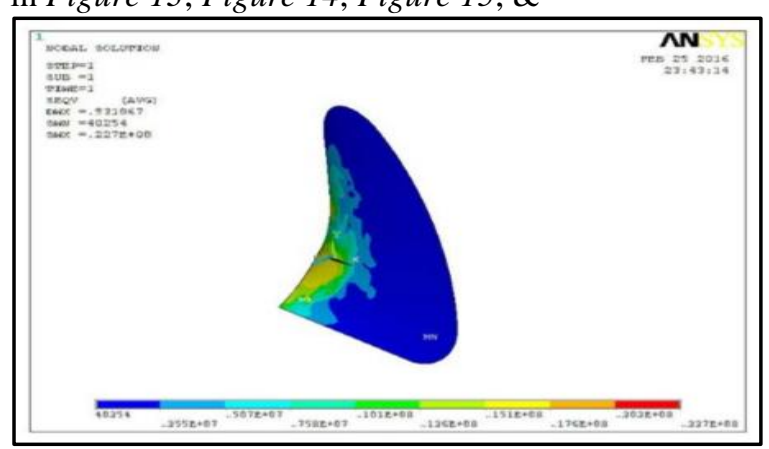

Figure 16.

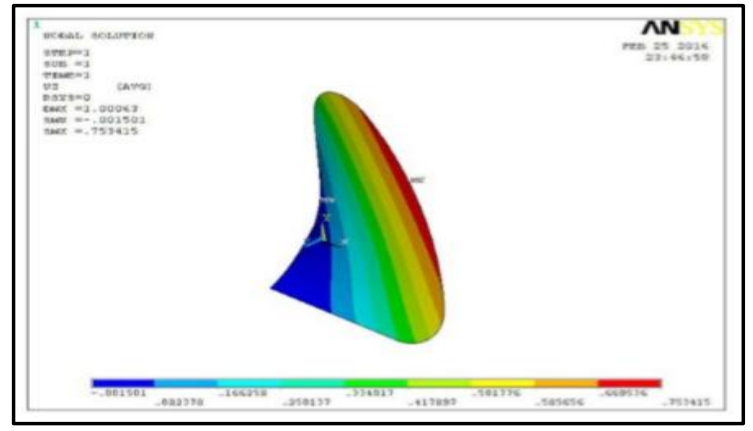

Figure 13. Deflection of CFRP blade (12 layers)

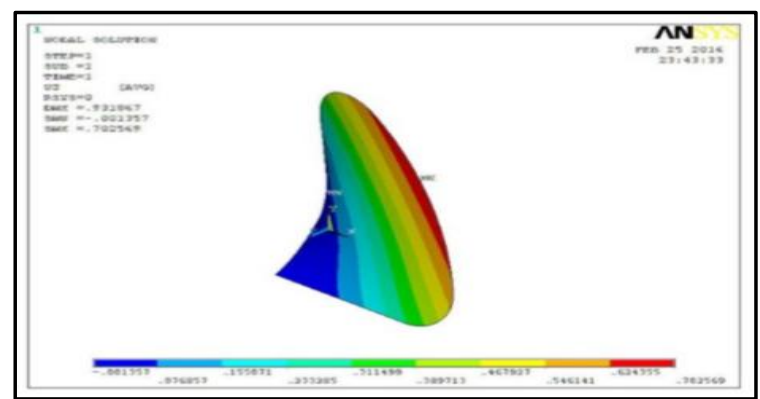

Figure 14. Deflection of hybrid composite blade (12 layers)

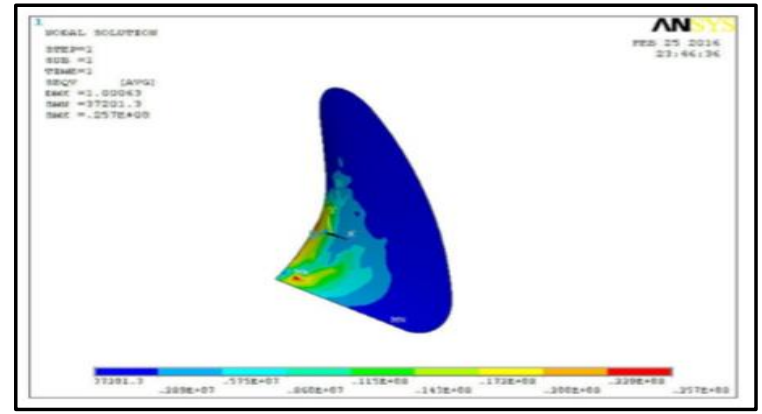

Figure 15. Max von/Mises stress for CFRP propeller blade (12 layers)

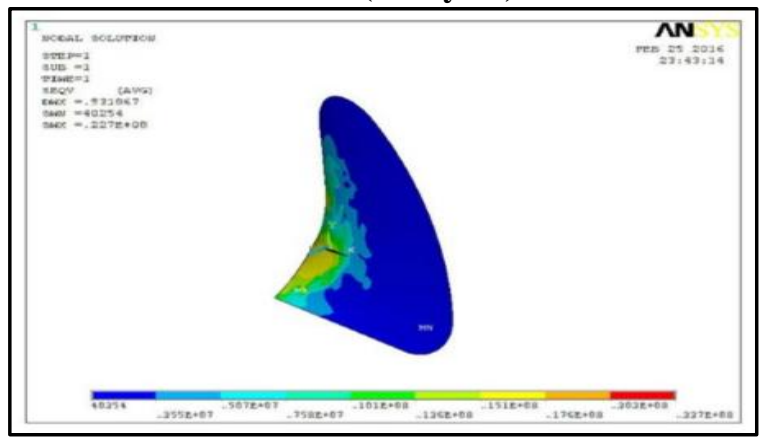

Figure 16. Max von/Mises stress for hybrid composite propeller blade (12 layers)

\section{Case 4: Analytical result for 12 covers}

Here the width of each coating is estimated as 0.0625 $\mathrm{mm}$. The maximum illumination for a single CFRP propeller blade i.e. I normal to the blade face is $0.811 \mathrm{~mm}$ and the maximum pressure of von Mises is $26.3 \mathrm{~N} / \mathrm{mm} 2$. In the case of a hybrid propeller mounting shaft at $0.9905 \mathrm{~mm}$ and von Mises weight is $25.2 \mathrm{~N} / \mathrm{mm} 2$. Both illumination and von/Mises stresses are illustrated below Figure 17, Figure 18, Figure 19, \& Figure 20.

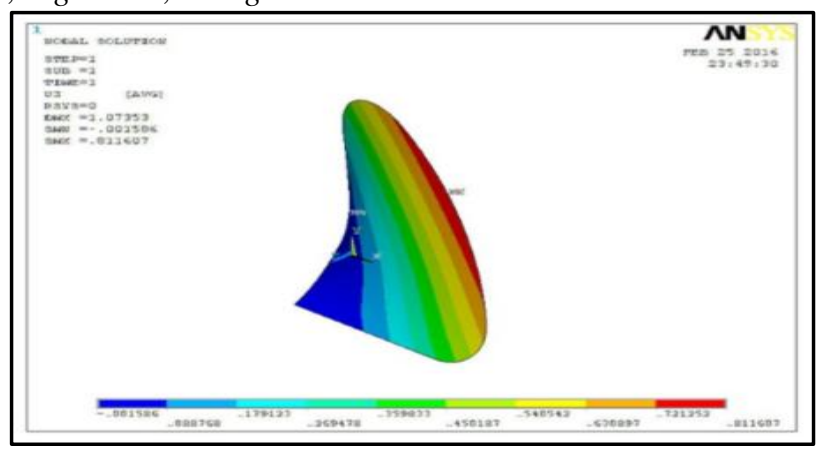

Figure 17. Deflection of CFRP blade (16 layers)

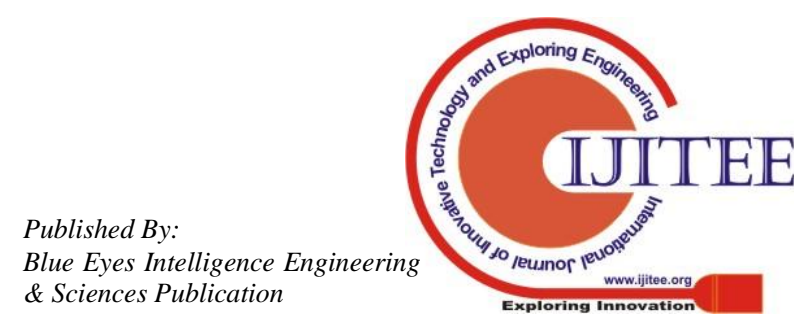




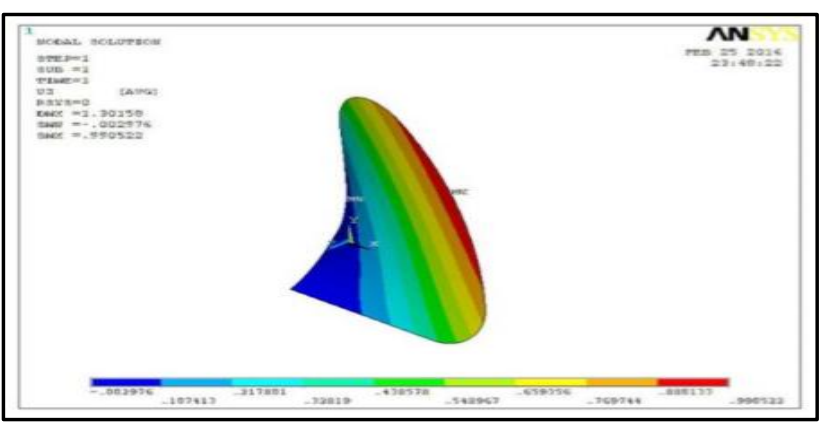

Figure 18. Deflection of hybrid composite blade (16 layers)

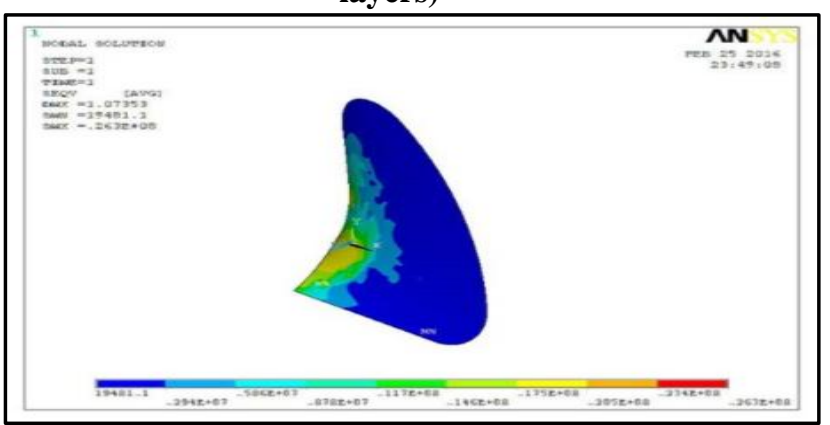

Figure 19. Max von Mises pressure/stress for CFRP propeller blade (16 layers)

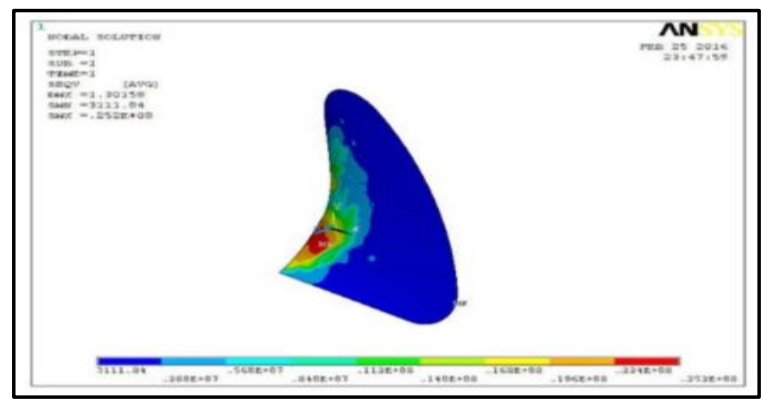

Figure 20. Max von Mises stress for hybrid composite propeller blade (16 layers)

\section{CONCLUSION}

From the present work the following conclusions are drawn:

$>\quad$ The average illumination for a CFRP propeller blade is approximately $0.77925 \mathrm{~mm}$, where it is similar to a hybrid propeller blade at $0.85107 \mathrm{~mm}$. Thus a suction increase in hybrid propeller is $9.21 \%$ smaller compared to propeller compound.

The average von Mises pressure developed in CFRP is $24.45 \mathrm{~N} / \mathrm{mm} 2$ whereas in a hybrid propeller $22.275 \mathrm{~N} /$ $\mathrm{mm} 2$. So weight reduction in a hybrid propeller blade is about $8.895 \%$.

\section{REFERENCES}

1. A. Nematollahi, A. Dadvand, and M. Dawoodian, "An axisymmetric underwater vehicle-free surface interaction: A numerical study," Ocean Eng., vol. C, no. 96, pp. 205-214, 2015.

2. P. Jagadeesh and K. Murali, "Rans Predictions of Free Surface Effects on Axisymmetric Underwater Body," Eng. Appl. Comput. Fluid Mech., vol. 4, no. 2, pp. 301-313, 2010.

3. A. Mitra, J. P. Panda, and H. V Warrior, "Experimental and numerical investigation of the hydrodynamic characteristics of Autonomous Underwater Vehicles over sea-beds with complex topography."
4. M. Salari and A. Rava, "Numerical investigation of hydrodynamic flow over an AUV moving in the water-surface vicinity considering the laminar-turbulent transition," J. Mar. Sci. Appl., vol. 16, no. 3, pp. 298-304, Sep. 2017.

5. Z. Dong, L. Wan, Y. Li, T. Liu, J. Zhuang, and G. Zhang, "Point Stabilization for an Underactuated AUV in the Presence of Ocean Currents," Int. J. Adv. Robot. Syst., vol. 12, no. 7, p. 100, Jul. 2015.

6. X. Yao, G. Yang, and Y. Peng, "Nonlinear Reduced-Order Observer-Based Predictive Control for Diving of an Autonomous Underwater Vehicle," Discret. Dyn. Nat. Soc., vol. 2017, pp. 1-15, Jan. 2017.

7. B. Subudhi, K. Mukherjee, and S. Ghosh, "A static output feedback control design for path following of autonomous underwater vehicle in vertical plane," Ocean Eng., vol. 63, no. 63, pp. 72-76, May 2013.

8. W.-Y. Gan, D.-Q. Zhu, W.-L. Xu, and B. Sun, "SURVEY OF TRAJECTORY TRACKING CONTROL OF AUTONOMOUS UNDERWATER VEHICLES,” J. Mar. Sci. Technol., vol. 25, no. 6, pp. 722-731, 2017

9. D. Rao and B. Reddy, "Modal Analysis Of Composite Propeller For Ships Application."

10. Y. S. R., "HARMONIC ANALYSIS OF COMPOSITE PROPELLER FOR MARINE APPLICATIONS," Int. J. Res. Eng. Technol., vol. 01, no. 03, pp. 257-260, Mar. 2012.

11. M. Ahmed Khan, K. shahnawaz uddin, and B. Ahmed, "Design and Dynamic analysis on composite propeller of ship using FEA,” Int. J. Adv. Trends Comput. Sci. Eng., vol. 2, no. 1, pp 310-315, 2013

12. A. Suraci, H. Louati, K. N. Culliton, and P. E. Beaulé, "Comparing In Vivo Performance of Two Highly Cross-Linked Polyethylene Thermal Treatments: Remelting vs Annealing in Acetabular Liners," J. Arthroplasty, vol. 34, no. 7, pp. 1509 1513, Jul. 2019.

13. K. Beng Yeo, W. Heng Choon, and W. Y. Hau, "Prediction of Propeller Blade Stress Distribution Through FEA,” J. Appl. Sci., vol. 14, no. 22, pp. 3046-3054, Dec. 2014.

14. Y. L. Young, "Fluid-structure interaction analysis of flexible composite marine propellers," J. Fluids Struct., vol. 24, no. 6, pp. 799-818, Aug. 2008.

15. M. Vidya Sagar, M. Venkaiah, and D. Sunil, "Static And Dynamic Analysis Of Composite Propeller Of Ship Using FEA." 